\title{
THEORETICAL ANALYSIS OF AN EXTERNAL GEAR PUMP -METHODS FOR DETERMINING THE PUMPING CAPACITY-
}

\author{
Mihai Avram ${ }^{1}$, Constantin Niţu ${ }^{1}$, Lucian Bogatu ${ }^{1}$, Valerian Sarbu ${ }^{1}$ \\ ${ }^{1}$ University Politehnica of Bucharest, Faculty of Mechatronics and Mechanical Engineering, \\ Mechatronics and Precision Engineering Department
}

E-mail: mavram02@yahoo.com

\begin{abstract}
Static and dynamic performances of a pump can be determined both theoretically and experimentally. Theoretical analysis implies to develop a mathematical model of the pump operation and the first step for its building is to define the theoretical pumping capacity.

The paper presents four distinct methods for pumping capacity calculation for external gear pumps, with numerical data applied, in order to compare the results. One of the methods allows for calculation of the pump instantaneous flow rate, by taking into consideration the structural parameters and the rotation speed of the driving shaft. This method is the one to be considered for a further development of the pump mode.
\end{abstract}

Keywords: External Gear Pump, Pumping Capacity, Theoretical Analysis, Tooth-Gap Area.

\section{Introduction}

Volumetric pumps are often used as power supplyforthe automatic hydraulic systems. Their principle of operation is based on the continuous volume change of their inner chambers (active chambers), due to the motion of an internal part, usually plunger, piston, vanes or membrane, relative to a fixed part.

There are many design options for volumetric pumps, but the external gear type is by far the most common. This fact is mainly due to the advantages these pumps possess as they are robust, have a relatively simple design and provide large flow rates and pressures.

This equipment type suffers from two undesired phenomena during normal operation: flow rate loss and asymmetrical forces [1]. These ones are proportional to the current working pressure. The flow rate losses occur due to the leakage of the working fluid from the high-pressure chamber to the low pressure one.

The asymmetric forces cause high stresses and deflections of the gear shafts and bearings, which put in contact the gear teeth and the housing, ending in power loss and wear. These forces are radially oriented and are the result of:

- local high overpressure generated by liquid "crushing" in the gap between two teeth of the engaged gears, when the gap volume diminish during motion;
- a hydrostatic imbalance, due to the high pressure acting on one side of the gears and low pressure acting on the opposite one; even there are methods to compensate this phenomenon, they are rarely applied due to the additional costs.

The flow rate leakage and asymmetric forces caused by hydrostatic imbalance influence all the volumetric devices, not only the gear pumps. It is the reason for which there is a large variety of performance specifications between the commercial models.

\section{Theoretical Analysis of an External Gear Pump}

The main goal of the paper is to describe the static and dynamic performance of the equipment, which can be determined by theoretical and experimental means.

The theoretical method is usually done by following the subsequent steps:

- Construct the mathematical model

- Simulate the pump operation

- Review and study the obtained results.

With the aim of constructing a thorough and accurate mathematical model, the use of simplifying scenarios was restricted. The mathematical model was written in accordance with the notations in Fig 1 and Table 1. 


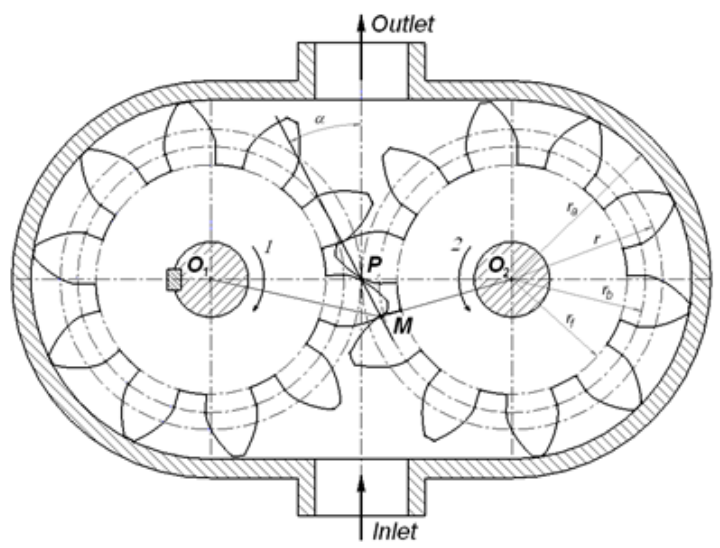

Figure 1

As a numerical example, it was opted for a pump whose parameters are well known, as it can be seen in the last column of Table 1.

\begin{tabular}{|c|c|c|c|}
\hline Parameter & $\begin{array}{c}\text { Symbol / Unit of } \\
\text { measurement }\end{array}$ & Equation & Value \\
\hline Tooth number & $\mathrm{z}[-]$ & - & 10 \\
\hline Modulus & $\mathrm{m}[\mathrm{mm}]$ & - & 3 \\
\hline Width & $\mathrm{b}[\mathrm{mm}]$ & - & 12 \\
\hline Coefficient of .. & $x[-]$ & - & 0.3 \\
\hline Pressure angle & $\alpha_{0}\left[{ }^{\circ}\right]$ & - & 20 \\
\hline Radius of pitch circle & $\mathrm{r}[\mathrm{mm}]$ & $\frac{m \cdot z}{2}$ & 15 \\
\hline Pressure angle on the tooth tip. & $\left.\alpha_{a}{ }^{\circ}\right]$ & $\arccos \left(\frac{r}{r_{C E}} \cdot \cos \alpha_{0}\right)$ & 41.773 \\
\hline Radius of the base circle & $\mathrm{r}_{\mathrm{b}}[\mathrm{mm}]$ & $r \cdot \cos \alpha_{0}$ & 14.095 \\
\hline Radius of tip circle & $\mathrm{r}_{\mathrm{a}}[\mathrm{mm}]$ & $\frac{m \cdot(z+2+2 \cdot x)}{2}$ & 18.90 \\
\hline Radius of root circle & $\mathrm{rf}_{\mathrm{f}}[\mathrm{mm}]$ & $\begin{array}{c}\frac{m \cdot\left[z-2 \cdot\left(1+c_{0}\right)+2 \cdot x\right]}{2} \\
C_{0}=0.25\end{array}$ & 12.15 \\
\hline $\begin{array}{l}\text { Tooth thickness on the pitch } \\
\text { circle }\end{array}$ & $\mathrm{S}_{\mathrm{d}}[\mathrm{mm}]$ & $m \cdot\left(\frac{\pi}{2}+2 \cdot x \cdot \tan \alpha_{0}\right)$ & 5.368 \\
\hline $\begin{array}{l}\text { Tooth thickness on the tip } \\
\text { circle }\end{array}$ & $\mathrm{s}_{\mathrm{a}}[\mathrm{mm}]$ & $2 \cdot r_{\alpha} \cdot\left(i n v \alpha_{0}-i n v \alpha_{a}+\frac{s_{d}}{2 \cdot r}\right)$ & 2.56 \\
\hline $\begin{array}{l}\text { Tooth thickness on the base } \\
\text { circle }\end{array}$ & $\mathrm{sb}[\mathrm{mm}]$ & $2 \cdot m_{b} \cdot\left(i n v \alpha_{0}+\frac{s_{d}}{2 \cdot r}\right)$ & 5.47 \\
\hline
\end{tabular}

The first step implies determining the pumping capacity relying on the theory alone.

Pumping capacity or the liquid volume/rotation, $V_{g P}\left[\mathrm{~cm}^{3} / \mathrm{rot}\right]$ is defined as the sum of all the volume changes of each active chambers of a pump, during an entire shaft rotation. It is evaluated without taking into consideration the tolerances, back 1 as hand deflections. Without any special mentions, $V_{g}$ is a purely theoretical value. Values for the geometrical pumping capacity are standardized and correspond to the normal string of numbers R10.

Real pumps have always a lower effective pumping capacity than that resulting from the theoretical analysis and it is usually determined experimentally by spinning the shaft of the pump by one rotation and measuring the discharged volume.
In the following paragraphs there will be presented a few methods for determining the pumping capacity and the instantaneous flow rate using theoretical means only.

The instantaneous flow rate is easily expressed using the following equation:

$q_{p}=10^{-3} \cdot V_{g p} \cdot n[\mathrm{l} / \mathrm{min}]$

where $n$ is defined as the pump shaft rotation speed, measured in rotations per minute [RPM].

\subsection{The first method}

This method begins from the following equation $[2,3]$ :

$$
V_{g P}=2 \cdot V_{g} \cdot z
$$


where $V_{g}$ is the volume of the gap between two adjacent teeth, the gear external diameter and the pump housing lids.

In a first approach, the gear assembly is considered to be stationary, and the $V_{\min }$ can be ignored, admitting in the same time (as a method of adjustment) that the inter-gear volume $V_{g}$ is equal to the one of the tooth, $V_{d}$. Therefore, it can be calculated:

$$
V_{g P}=2 \cdot b \cdot \frac{\pi}{2}\left(r_{c}^{2}-\eta_{f}^{2}\right)
$$

Where the notations are indicated in the table 1.

In the case of a standard gear, without addendum modification, the following equation can be written:

$$
r_{a}=m \cdot \frac{z}{2}+m, r_{f} \cong m \cdot \frac{z}{2}-m
$$

As a result, the new equation describing the geometrical pump capacity is:

$$
\begin{aligned}
& V_{g p}=2 \cdot b \cdot \frac{\pi}{2}\left[\left(m \cdot \frac{z}{2}+m\right)^{2}-\left(m \cdot \frac{z}{2}-m\right)^{2}\right]=2 \cdot \pi \cdot \\
& b \cdot m^{2} \cdot z
\end{aligned}
$$

Equation (5) outlines the desire for choosing a high module for the gear tooth, because for a given center distance of a gear $(a=m * z)$, the resulting pumping capacity is proportional to the module.

For the chosen gear assembly, with the parameters given in Table 1 , it is obtained the following pumping capacity:

$$
V_{g P}=2 \cdot \pi \cdot 10 \cdot 3^{2} \cdot 12=5654 \mathrm{~mm}^{2}=6.785 \mathrm{~cm}^{2}
$$

\subsection{The second method}

The more precise assessment of the pumping capacity involves knowing the tooth gear geometry and studying of the tooth meshing. The tooth profile is made with an in volute curve in most situations due to the properties it possesses that simplify the manufacturing processes. The in volute (Fig. 2) is the path described by a point $\mathrm{M}_{\mathrm{y}}$, belonging to a straight

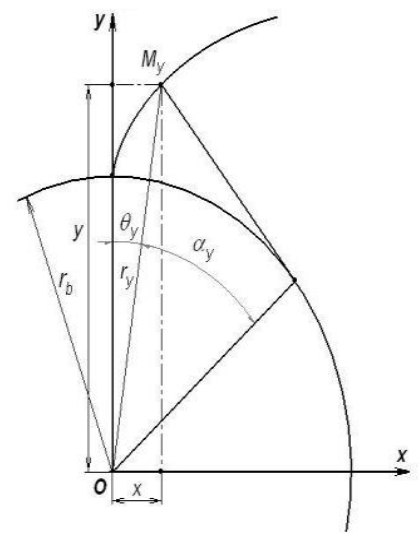

Figure 2

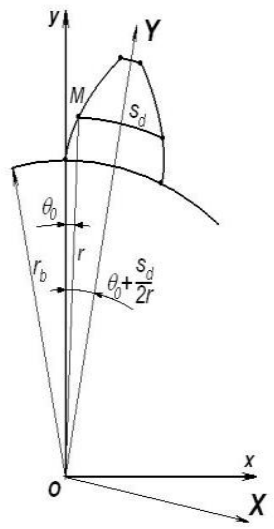

Figure 3 line, when it rolls, without slippage, on a fixed circle, called base circle, with the radius, $r_{b}$.

The parametric equations of the involute are [4, $5,6]$ :

$$
\left\{\begin{array}{l}
r_{y}=\frac{r_{b}}{\cos \alpha_{y}} \\
\theta_{y}=i n v \alpha_{y}=\tan \alpha_{y}-\alpha_{y}
\end{array}\right.
$$

By removing the variable $\alpha_{y}$, the in volute equation in polar coordinates can be got: $r_{y}=f\left(\theta_{y}\right)$.

Similarly, the in volute equations in cartesian coordinates about the xOy frame (Fig. 3) are:

$$
\left\{\begin{array}{l}
x=r_{y} \cdot \sin \theta_{y}=\frac{r_{b}}{\cos \alpha_{y}} \cdot \sin \left(i n v \alpha_{y}\right) \\
y=r_{y} \cdot \cos \theta_{y}=\frac{r_{b}}{\cos \alpha_{y}} \cdot \cos \left(i n v \alpha_{y}\right)
\end{array}\right.
$$

If the coordinate frame $\mathrm{xOy}$ is rotated by an angle of $\varphi$ to the coordinate frame XOY, the equations of the in volute coordinates become:

$$
\left[\begin{array}{l}
X \\
Y
\end{array}\right]=\left[\begin{array}{cc}
\cos \varphi & -\sin \varphi \\
\sin \varphi & \cos \varphi
\end{array}\right] \cdot\left[\begin{array}{l}
x \\
y
\end{array}\right]
$$

or:

$$
\left\{\begin{array}{l}
X=x \cdot \cos \varphi-y \cdot \sin \varphi \\
Y=x \cdot \sin \varphi+y \cdot \cos \varphi
\end{array}\right.
$$

Where:

$$
\varphi=i n v \alpha_{0}+\frac{s_{d}}{2-r}
$$

As already explained, hydraulic fluid is transported from intake area to the output by the gaps between the gear teeth. Their volume can be expressed by the equation:

$$
V_{g}=\frac{\pi \cdot\left(r_{a}^{2}-r_{f}^{2}\right)}{z} \cdot b-V_{d}
$$

Where $V_{d}$ is the volume of one tooth.

Next, a method for determining that volume is employed; as a first step the $V_{d}$ volume is determined and it has the following expression:

$$
V_{d}=V_{d e}+V_{d b}
$$

Where $V_{d e}$ is the volume of the tooth where its profile is an in volute and $V_{d b}$ is the volume of the tooth located between the base circle and the root circle. The latter has a trochoid shape of the root, but usually this is simplified.

For determining the volume $V_{d e}$ three approaches will be explored. 


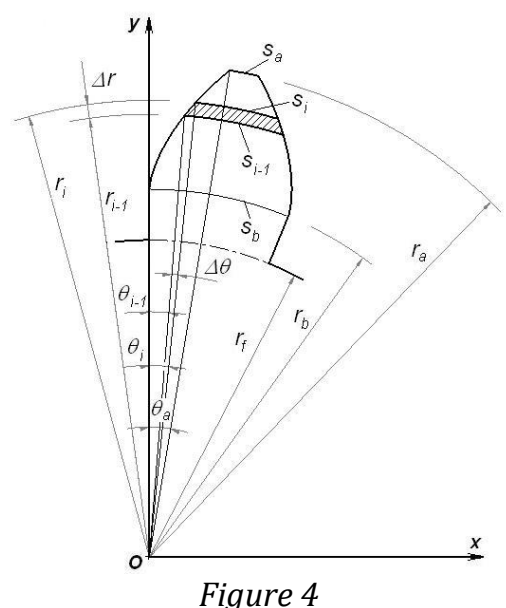

First approach requires to divide the angle $\theta_{a}$ by a value $n$, with the resulting increment equal to $\Delta \theta=\frac{\theta_{a}}{n}$.

Given an angle $\theta_{i}=i \cdot \Delta \theta$ the length of the arch on the root circle of radius $r_{i}$ will be $s_{i}$, and for the angle $\theta_{i-1}=(i-1) \cdot \Delta \theta$ the length of the arch of radius $r_{i-1}$ will be $s_{i-1}$.

The basic volume $\Delta V_{i}$ can be approximated by:

$$
\Delta V_{i} \approx \frac{s_{i}+s_{i-1}}{2} \cdot\left(r_{i}-r_{i-1}\right) \cdot b
$$

Therefore, the arch segments $s_{i}$ can be expressed using the given equation (14):

$$
\Varangle M_{o} O y=\theta_{0}+\frac{\nabla_{d}}{2 \cdot r}=\theta_{i}+\frac{s_{i}}{2-r_{i}}
$$

Where: $\theta_{0}=i n v \alpha_{0}=\tan \alpha_{0}-\alpha_{0}$

$$
r_{i}=\frac{r_{b}}{\cos \alpha_{i}^{i}} \text {. }
$$

$\alpha_{I}$ is found by solving the equation $\theta_{i}=\tan \alpha_{i}-\alpha_{i}$. An approximate solution for this equation has the following formula[7]:

$$
\begin{aligned}
& \alpha_{i}=\left(3 \cdot \theta_{i}\right)^{\frac{1}{a}}-\frac{2}{5} \cdot \theta_{i}+\frac{9}{175} \cdot 3^{\frac{2}{a}} \cdot \theta_{i}^{\frac{5}{3}}-\frac{2}{175} . \\
& 3^{\frac{1}{a}} \cdot \theta_{i}^{\frac{7}{8}}-\frac{144}{67375} \cdot \theta_{i}^{3}+\frac{3258}{3128125} \cdot 3^{\frac{2}{3}} \cdot \theta_{i}^{\frac{11}{3}}-\cdots
\end{aligned}
$$

This approximation keeps a high accuracy, only if $\theta_{i}<1.8 \mathrm{rad}$.

For calculating $S i$ it is necessary to start with the condition stated in (14):

$$
s_{i}=2 \cdot\left(\theta_{0}-\theta_{i}+\frac{s_{d}}{2 \cdot r}\right) \cdot r_{i}
$$

The volume of the tooth in the area where the tooth profile is in volute is therefore:

$$
V_{\text {de }}=\sum_{i=1}^{n} \Delta V_{i}
$$

When the root circle radius $r_{f}$ is smaller than the base circle $r_{b}$, that section of the tooth profile cannot be defined by an in volute.
A linear profile, oriented to the gear center (hypocycloid) is recommended and the additional volume $V_{d b}$ is therefore defined by:

$$
V_{d b}=\frac{s_{b}+s_{f}}{2} \cdot\left(r_{b}-r_{f}\right) \cdot b
$$

here $s b$ is the length of the arch present on the base circle and $s_{f}$ the length of the arch on the root circle. The two lengths have the following equations:

$$
\begin{aligned}
& s_{b}=2 \cdot\left(\theta_{0}+\frac{s_{d}}{2 \cdot r}\right) \cdot r_{b} \\
& s_{f}=2 \cdot\left(\theta_{0}+\frac{s_{d d}}{2 \cdot r}\right) \cdot r_{f}
\end{aligned}
$$

Now, it is possible to proceed for calculating the volumes $V_{d}$ and $V_{g}$. The resulting pumping capacity will then have the equation:

$$
V_{g P}=2 \cdot V_{g} \cdot z \cdot 10^{-3}\left[\mathrm{~cm}^{3}\right]
$$

Figure 5 presents the algorithm that enables the calculation of the area through this method

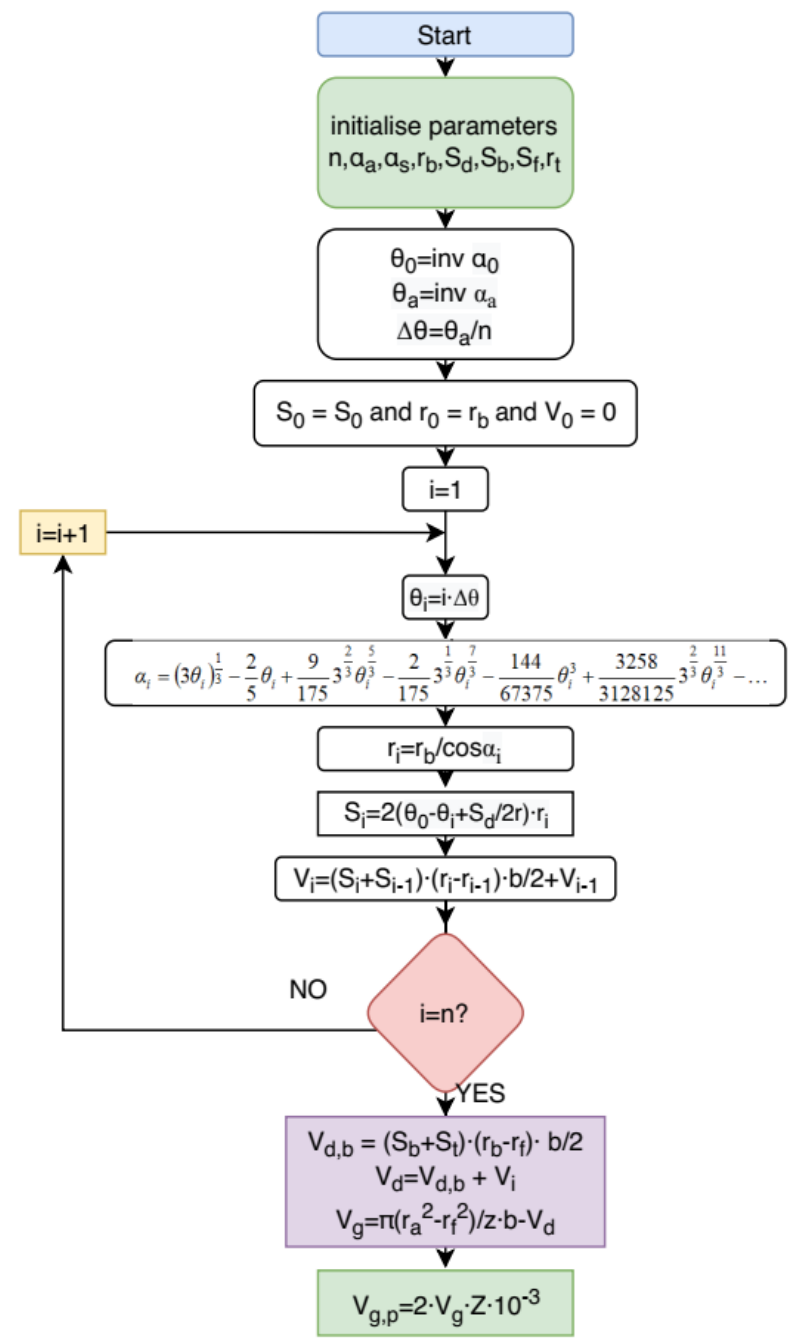

Figure 5

By use of this algorithm, a function in the MATLAB environment was implemented. Calling this function, 
it finally returned the following results: $V_{d}=$ $347.2504 \mathrm{~mm}^{3}, V_{g}=442.8759 \mathrm{~mm}^{3}, V_{g P}=8.8575 \mathrm{~cm}^{3}$.

The second approach is similar to the first, as it involves dividing the tooth profile in $n$ volume subsections, $\Delta V_{i}$ (fig. 4). The difference consists of the way of defining the volume element, which is calculated with the following equation:

$$
\begin{aligned}
& \Delta V_{i}=\frac{r_{i}^{2}-r_{i-1}^{2}}{2} \cdot \frac{s_{i}}{2 \cdot r_{i}} \cdot b=\frac{r_{i}^{2}-r_{i-1}^{2}}{2} \cdot\left[\theta_{0}-\theta_{i}+\right. \\
& \left.\frac{s_{d}}{2-r}\right] \cdot b
\end{aligned}
$$

Where:

$r_{i-1}=r_{b}+(i-1) \cdot \Delta r_{;} \quad r_{i}=r_{b}+i \cdot \Delta r_{;}$

and $\Delta r=\frac{r_{a}-r_{b}}{n}$ - the increment value; $n$ - the number of increments.

The resulting equation is:

$$
\begin{aligned}
& V_{d e}=b \cdot \sum_{i=1}^{n}\left[\frac{\Delta r-\left(2-r_{b}+2 \cdot i \cdot \Delta r-\Delta r\right)}{2} .\right. \\
& \left.\left(\theta_{0}-\theta_{i}+\frac{s_{d}}{2-r}\right)\right]
\end{aligned}
$$

Where:

$$
\begin{aligned}
& \theta_{i}= \\
& \tan \left[\arccos \left(\frac{r_{b}}{r_{b}+i \cdot \Delta r}\right)\right]-\arccos \left(\frac{r_{b}}{r_{b}+i \cdot \Delta r}\right)
\end{aligned}
$$

For determining the desired inter-teeth surface, volume between two adjacent teeth and the pumping capacity, a MATLAB function was implemented; it yielded the following results:

$V_{d}=350.0588 \mathrm{~mm}^{3}, V_{g}=440.0675 \mathrm{~mm}^{3}, V_{g P}=8.8013$ $\mathrm{cm}^{3}$.

The third approach involves determining the section of a tooth as seen in fig. 6, defined as the sum of three surfaces:

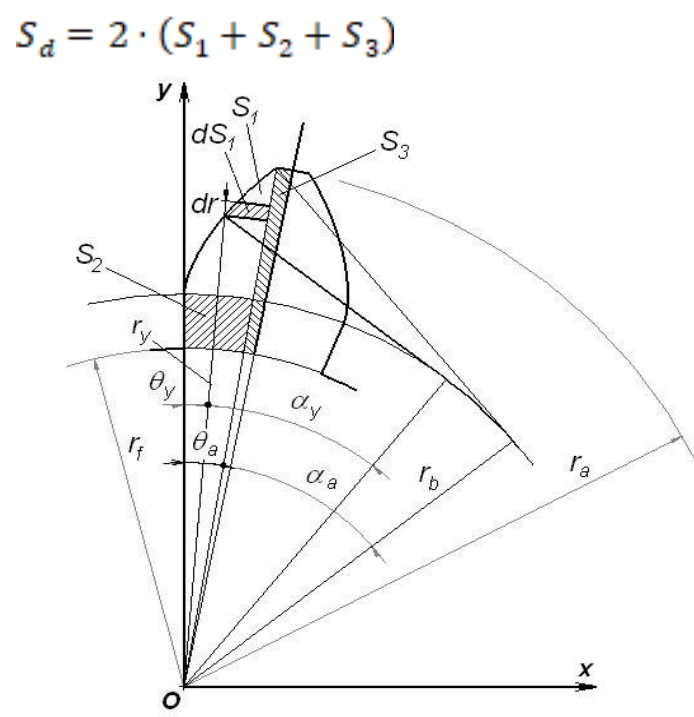

Figure 6

In the triangle $\triangle O M P$ someone can assert:

$$
r_{y}=\frac{r_{b}}{\cos \alpha_{y}}
$$

By differentiating (26), it results:

$$
d r_{y}=\frac{r_{b} \cdot \sin \alpha_{y}}{\cos ^{2} \alpha_{y}} \cdot d \alpha_{y}
$$

The elementary area $d S_{1}$ can be calculated with the following equation:

$$
d S_{1}=\left(\theta_{a}-\theta_{y}\right) \cdot r_{y} \cdot d r_{y}
$$

By replacing (26) and (27) in (28), it results:

$$
d S_{1}=\left(\theta_{a}-\theta_{y}\right) \cdot \frac{r_{b}^{2} \cdot \sin \alpha_{y}}{\cos ^{3} \alpha_{y}} \cdot d \alpha_{y}
$$

Further integrating (29), it results:

$S_{1}=\int_{0}^{\alpha_{a}}\left(\theta_{a}-\tan \alpha_{y}+\alpha_{y}\right) \cdot \frac{r_{b}^{2} \cdot \sin \alpha_{y}}{\cos ^{3} \alpha_{y}} \cdot d \alpha_{y}$

Expanding and resolving, finally it is obtained:

$$
\begin{aligned}
& S_{1}=r_{b}^{2} \cdot\left[\theta_{a} \cdot\left(\frac{1}{2-\cos ^{2} \kappa_{a}}-0,5\right)-\frac{\operatorname{tg}^{a} \alpha_{a}}{3}+\right. \\
& \left.\frac{\omega_{a}}{2-\cos ^{2} \alpha_{a}}-\frac{\operatorname{tg} \omega_{a}}{2}\right]
\end{aligned}
$$

The other two sections are also defined using the following equations:

$$
\begin{aligned}
& S_{2}=\frac{r_{b}^{2}-r_{f}^{2}}{2} \cdot \theta_{a} \\
& S_{3}=\frac{r_{a}^{2}-r_{f}^{2}}{2} \cdot\left[\theta_{0}-\theta_{a}+\frac{s_{d}}{2 \cdot r}\right]
\end{aligned}
$$

Therefore, the resulting tooth gap volume of $V_{g}$ is derived as:

$$
V_{g}=\frac{\pi \cdot\left(r_{a}^{2}-r_{f}^{2}\right)}{z} \cdot b-2 \cdot\left(S_{1}+S_{2}+S_{3}\right) \cdot b
$$

And the pumping capacity can be calculated with the equation (21).

This method yields the following results:

$V_{d}=350.1388 \mathrm{~mm}^{3}, V_{g}=439.9875 \mathrm{~mm}^{3}, V_{g P}=8.7997$ $\mathrm{cm}^{3}$.

\subsection{The third method}

This method takes advantage of the computer assisted design environments, specifically Solid works. It involves drawing the gear tooth profile and extruding it to get a 3D shape. Figure 7 shows the 3D model of the tooth with in volute profile. Bu help the measure tool, it is possible to determine the area of the surfaces, as well as the volume.

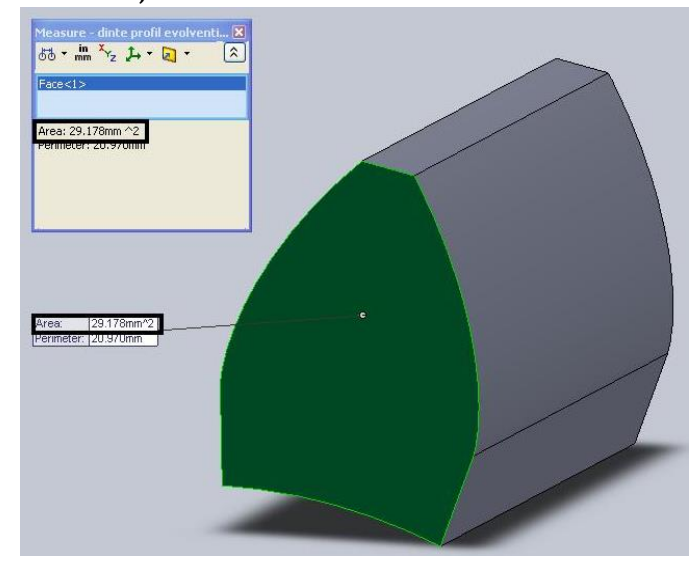

Figure 7 
The obtained results are $V_{d}=350.1323 \mathrm{~mm}^{3}, V_{g}=$ $439.9940 \mathrm{~mm}^{3}, V_{g P}=8.7999 \mathrm{~cm}^{3}$.

\subsection{The fourth method}

This method refers to notations in the fig. 1 . In this drawing, the driving gear (1) enables the rotation of the driven gear (2). The contact point of two teeth at any moment in time is marked with $M$.

The instantaneous flow rate is computed with the following equation $[2,8]$ :

$$
q_{i}=q_{A B}+q_{E F}-q_{L M}-q_{M N}
$$

Where:

$$
\begin{aligned}
& q_{A B}=q_{E F}=b \cdot\left(r_{a}-r_{f}\right) \cdot \frac{r_{a}+r_{f}}{2} \cdot \omega=b \cdot \\
& \frac{r_{a}^{2}-r_{f}^{2}}{2} \cdot \omega \\
& q_{L M}=b \cdot\left(O_{2} M-r_{f}\right) \cdot \frac{o_{2} M+r_{f}}{2} \cdot \omega=b \cdot \\
& \frac{o_{2} M^{2}-r_{f}^{2}}{2} \cdot \omega \\
& q_{M N}=b \cdot\left(o_{1} M-r_{f}\right) \cdot \frac{o_{1} M+r_{f}}{2} \cdot \omega=b . \\
& \frac{o_{1} M^{2}-r_{f}^{2}}{2} \cdot \omega
\end{aligned}
$$

In these circumstances, the instantaneous flow rate will be defined by:

$$
q_{i}=b \cdot\left(2 \cdot \frac{r_{a}^{2}-r_{f}^{2}}{2}-\frac{o_{2} M^{2}-r_{f}^{a}}{2}-\frac{o_{1} M^{2}-r_{f}^{3}}{2}\right) \cdot \omega
$$

or:

$$
q_{i}=b \cdot\left(r_{a}^{2}-\frac{o_{2} M^{2}+o_{1} M^{2}}{2}\right) \cdot \omega
$$

In triangle $\triangle O_{1} M O_{2}$ (fig. 8) the segment PM is the median; the equation for the median length follows:

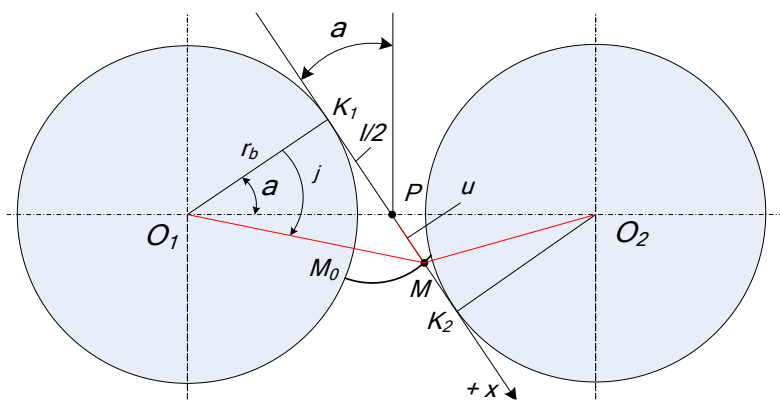

Figure 8

$$
\begin{aligned}
& \text { 4. } M P^{2}=2 \cdot\left(O_{1} M^{2}+O_{2} M^{2}\right)-O_{1} O_{2}{ }^{2} \\
& \text { hence: } \\
& O_{1} M^{2}+O_{2} M^{2}=2 \cdot u^{2}+2 \cdot r^{2}
\end{aligned}
$$

Given the newly defined equations, the instantaneous flow rate becomes:

$$
q_{i}=b \cdot\left(r_{a}^{2}-r^{2}-u^{2}\right) \cdot \omega
$$

The segment denoted byu (Fig 8) can be expressed as a function to the angular position $\varphi$ of the driving gear:

$$
u=\overline{P M}=\overline{K_{1} M}-\overline{K_{1} P}
$$

As the curve $M M$ ois an in volute, its properties lead to the following equation:

$$
\widehat{K_{1} M_{0}}=\overline{K_{1} M}=r_{b} \cdot \varphi
$$

In the triangle $\Delta O_{1} P K_{2}$ it can be written:

$\overline{K_{1} P}=\frac{l}{2}=r_{b} \cdot \tan \alpha$

By replacing the segments $K_{1} M$ and $K_{1} P_{v}$ it results:

$u=r_{b} \cdot \varphi-r_{b} \cdot \tan \alpha=r_{b} \cdot(\varphi-\tan \alpha)$

Now, the instantaneous flow rate will have the updated equation

$$
q_{i}=b \cdot\left[r_{a}^{2}-r^{2}-r_{b}^{2} \cdot(\varphi-\tan \alpha)^{2}\right] \cdot \omega
$$

When the first tooth engages with the driven tooth, the aforementioned equation is valid for the interval $u \in\left[-\frac{p_{b}}{2},+\frac{p_{b}}{2}\right]$. The value of $p_{b}$ for the given gear is:

$$
p_{b}=\frac{2-\pi}{z} \cdot r_{b}=\frac{2-\pi}{10} \cdot 14.095=8.8561 \mathrm{~mm}
$$

Meaning that $u \in[-4.4281,+4.4281]$.

In this case,(37) becomes:

$$
\frac{q_{1}}{\omega}=k_{1}-b \cdot u^{2}
$$

Where:

$$
k_{1}=b \cdot\left(r_{a}^{2}-r^{2}\right) \text {. }
$$

For the values of the parameters presented in Table 1 , the constant $k_{1}$ can be determined and it has the value, $k_{1}=1586.52 \mathrm{~mm}^{3}$.

By use of the plotting tool: "MAFA Plotter de Grafice Matematice", a graph was built, shown in fig. 9.

Maximum flow rate is obtained when $u=0$ and it can be expressed as:

$$
\frac{q_{i m a x}}{\omega_{1}}
$$

Minimum flow rate is obtained for $u= \pm \frac{p_{b}}{2}$ and it is expressed as:

$$
\frac{q_{i, \min }}{\omega}=k_{1}-b \cdot\left(\frac{p_{b}}{2}\right)^{2}
$$

For the gear assembly in question the results are:

$$
\begin{aligned}
& q_{i, \max }=1.58652 \cdot \omega\left[\frac{\mathrm{cm}^{3}}{s}\right] \\
& q_{i, \min }=1.35123 \cdot \omega\left[\frac{\mathrm{cm}^{3}}{s}\right]
\end{aligned}
$$

The average value of an integrable function, $f(x)$, on the interval $[a, b]$ is:

$$
\bar{f}=\frac{1}{b-a} \int_{a}^{b} f(x) d x .
$$




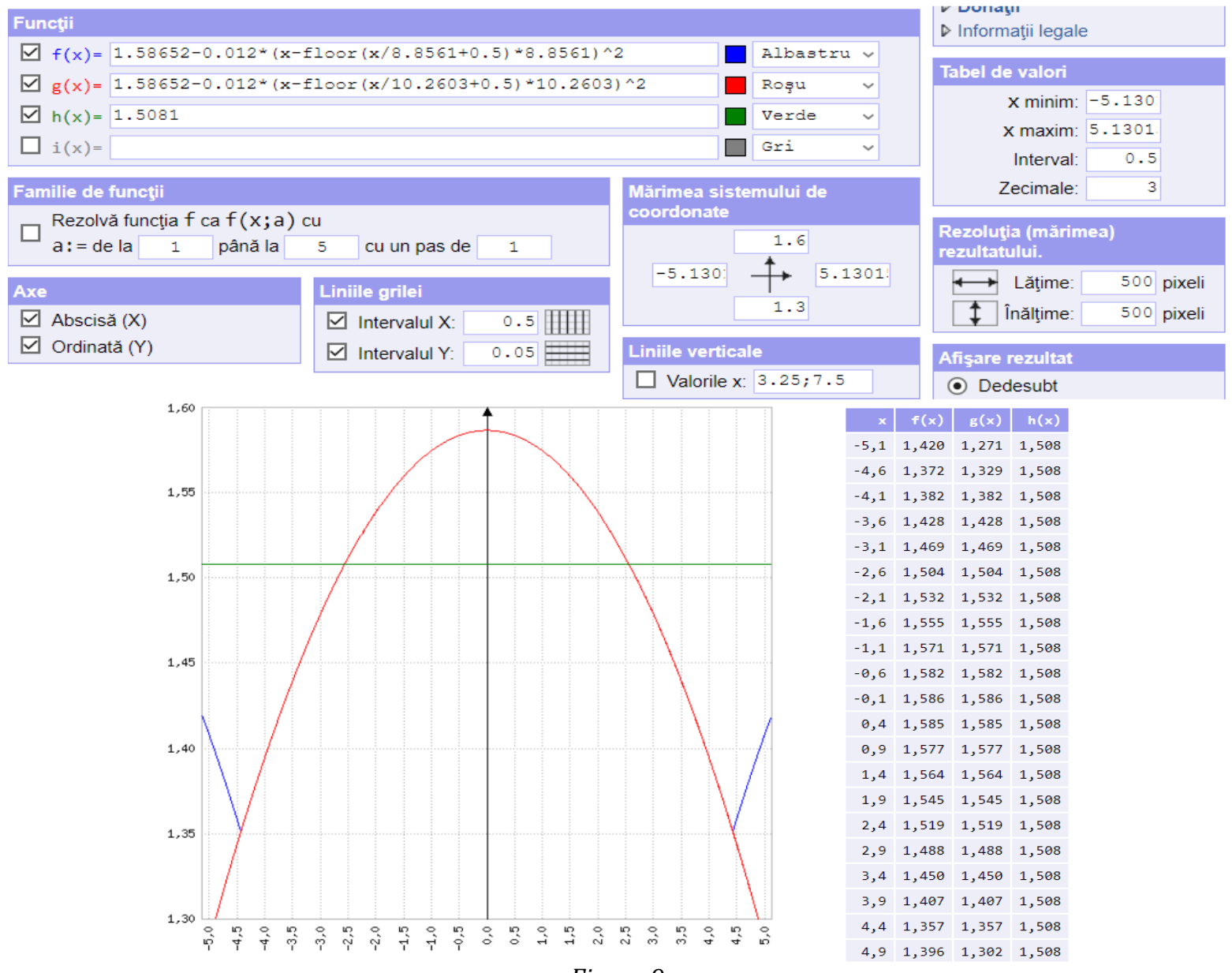

Figure 9

By using this method for a given angular velocity, the average value for the function

$$
\frac{q_{P}}{\omega}=f(u)=k_{1}-b \cdot u^{2} \quad \text { can be determined: }
$$$$
\frac{\overline{q_{P}}}{\omega}=\frac{2}{p_{b}} \cdot \int_{0}^{\frac{p_{i}}{2}}\left(k_{1}-b \cdot u^{2}\right) \cdot d u=k_{1}-\frac{1}{12} \cdot b \cdot p_{b}^{2}
$$

If (32) is applied to the assembly in question, the result is:

$$
\overline{q_{P}}=1.5081 \cdot \omega\left[\frac{\mathrm{cm}^{3}}{\mathrm{~s}}\right] .
$$

Where:

$$
\omega=\frac{2 \cdot \pi \cdot n}{60}\left[\frac{\mathrm{rad}}{\mathrm{s}}\right]
$$

With the past result it can be concluded that the instantaneous flow rate is about:

$$
\overline{q_{P}}=1.5081 \cdot \frac{2 \cdot \pi \cdot n}{60} \quad\left[\frac{\mathrm{cm}^{3}}{\mathrm{~s}}\right]=9.4757 \cdot n \quad\left[\frac{\mathrm{cm}^{3}}{\min }\right]
$$

Comparing this equation with the one expressed by (1), it can be validated without a doubt that the calculated pumping capacity for this pump is equal to: $9.4757 \mathrm{~cm}^{3}$.
The flow rate ripple has the amplitude:

$$
\delta q=\frac{q_{\max }-q_{\min }}{\overline{q_{P}}}=\frac{1.5865 \cdot \omega-1.3512 \cdot \omega}{1.5081 \cdot \omega}=0.156
$$

Given any tooth $i$, where $i$ is located in the interval $\{1 \ldots z\}$, any tooth will be engaged for a total angular rotation of:

$$
\varphi \in\left[(2 \cdot i-1) \cdot \frac{\pi}{z},(2 \cdot i+1) \cdot \frac{\pi}{z}\right]
$$

During a complete rotation, the teeth will engage successively, and the resulting flow rate of the pump will have a ripple (fig.10) that follows the equation:

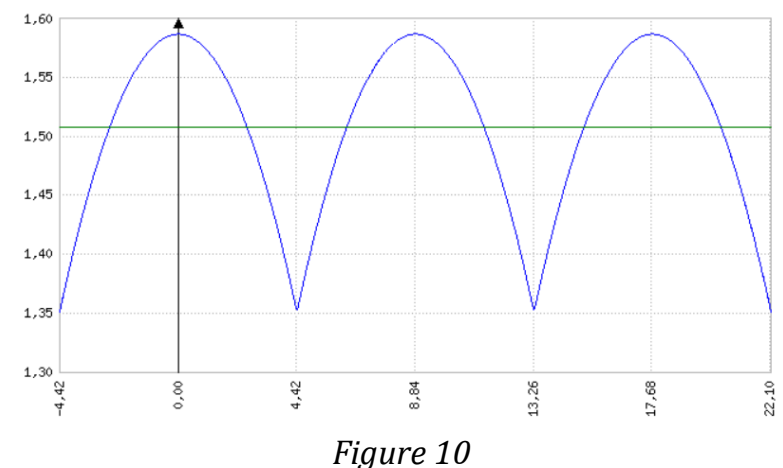




$$
q_{i}=\left\{k_{1}-b \cdot\left[u-\left[\frac{u}{p_{b}}+0.5\right] \cdot p_{b}\right]^{2}\right\} \cdot \omega
$$

Flow rate can also be expressed in relation to the angle of rotation $\varphi$ :

$$
q_{i}=b \cdot\left\{k_{1}^{*}-k_{2} \cdot\left[\varphi-k_{3}-\left[\frac{\varphi-k_{3}}{\varphi_{p}}+0.5\right] \cdot \varphi_{p}\right]^{2}\right\} \cdot \omega\left[\frac{\mathrm{cm}^{3}}{s}\right]
$$

or:

$$
q_{i}=0.0063 \cdot b \cdot\left\{k_{1}^{*}-k_{2} \cdot\left[\varphi-k_{3}-\left[\frac{\varphi-k_{3}}{\varphi_{p}}+0.5\right] \cdot \varphi_{p}\right]^{2}\right\} \cdot n\left[\frac{l}{\min }\right]
$$

Where:

$$
\begin{aligned}
& k_{1}^{*}=r_{a}^{2}-r^{2} \\
& k_{2}=r_{b}^{2} \\
& k_{3}=\tan \alpha_{0} \\
& \varphi_{p}=\frac{2 \cdot \pi}{z}
\end{aligned}
$$

For the geometry of the gear assembly, there were $\quad$ considered: $\quad k_{1}^{*}=1.9867 \mathrm{~cm}^{2}$, $k_{2}=1.9867 \mathrm{~cm}^{2}, \quad b=1.2 \mathrm{~cm}, \quad k_{3}=0.364$ and $\varphi_{p}=0.6283$.

Figure 11 shows the results.

\section{Funeții}
$\square f(x)=1.2 *(1.3221-1.9867 *(x-0.364-f 100 r((x-0.364) / 0.6283+0.5$
$\square g(x)=1.35$
$\square h(x)=1.587$
$\square i(x)=1.508$

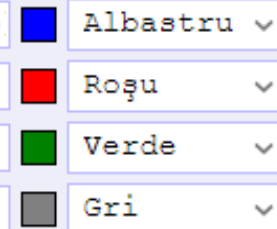

\section{Familie de funcţii}

Rezolvă funcţia $f$ ca $f(x ; a) c u$

a: = de la 1 până la 5 cu un pas de 1

\section{Axe}

\section{$\square$ Abscisă $(X)$ \\ $\square$ Ordinată $(Y)$}

\section{Linille grilei}

\begin{tabular}{l|r|}
$\square$ Intervalul $\mathrm{X}:$ & 0.1 \# \\
$\square$ Intervalul $\mathrm{Y}:$ & $0.05=$
\end{tabular}

Mărimea sistemului de coordonate

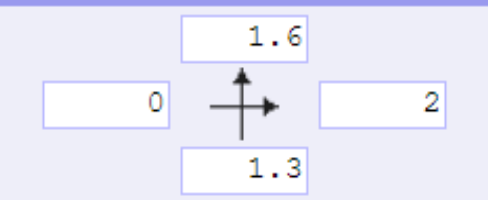

Linille verticale

Valorile $\mathrm{x}: 3.25 ; 7.5$

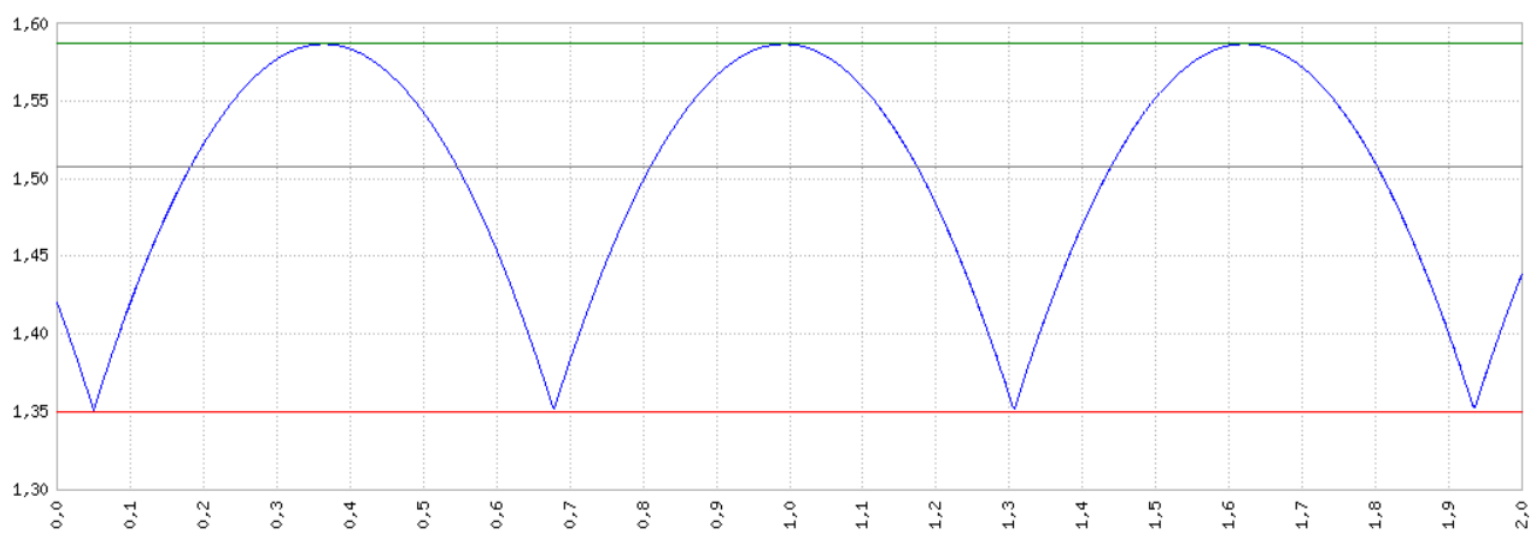

Figure 11 


\section{Conclusions}

The results obtained after applying the above presented methods, can be seen in the table 3 .

\begin{tabular}{|c|c|c|c|}
\hline Method & $\begin{array}{c}\text { Tooth volume } V_{d} \\
{\left[\mathrm{~mm}^{3}\right]}\end{array}$ & $\begin{array}{c}\text { Tooth gap volume 3 } \\
V_{g}\left[\mathrm{~mm}^{3}\right]\end{array}$ & $\begin{array}{c}\text { Displacement } \\
V_{g}\left[\mathrm{~cm}^{3}\right]\end{array}$ \\
\hline Method1 & - & - & 6.785 \\
\hline Method2 & 347.2504 & 442.8759 & 8.8575 \\
- Approach 1 & 350.0588 & 440.0675 & 8.8013 \\
- Approach2 & 350.1388 & 439.9875 & 8.7997 \\
- Approach 3 & 350.1323 & 439.9940 & 8.7999 \\
\hline Method3 & - & - & 9.4757 \\
\hline Method4 & & & \\
\hline
\end{tabular}

The pump considered for this analysis is powered by an asynchronous electrical motor, running at a constant angular speed. By use of an inverter, the rotor speed can be controlled and, as consequence, also the flow rate of the pump.

The value of the pumping capacity, found by exploring all methods, is fairly close to the one disclosed by the manufacturer $\left(8.6 \mathrm{~cm}^{3}\right)$, determined experimentally.

\section{References}

[1] Avram, M., Acţionări hidraulice și pneumatice Echipamente ş isisteme clasice şi mecatronice, Editura Universitară, Bucureşti, 2005;

[2] Vasiliu, N., Vasiliu, D., Acţionări hidraulice şi pneumatice, Volumul I, București, 2004;

[3] Ghionea, I.G., Ionescu, N.,Ghionea, A., Cuković, S., Tonoiu, S., Catană, M., Jamshed, I., Computer Aided Parametric Design of Hydraulic Gear
Pumps, Applied Mathematics, Mechanics, and Engineering, Vol. 60, Issue I, March, 2017

[4] Traian Demian, Elemente constructive de mecanica fina, Editura Didactica si Pedagogica, Bucuresti, 1980;

[5] Faydor L. Litvin, Alfonso Fuentes, Gear Geometry and Applied Theory, SECOND EDITION, Cambridge University Press, 2004;

[6] Xiaoru Hao, Xiaojun Zhou, Xiaoguang Liu and Xiaohu Sang, Flow characteristics of external gear pumps considering trapped volume, Advances in Mechanical Engineering 2016, Vol. 8(10) 1-10, 2016, DOI: 10.1177/1687814016674100;

[7] Cheng, H. H., Derivation of the Explicit Solution of the Inverse Involute Function and its Applications in Gear Tooth Geometry Calculations, Journal of Applied Mechanisms and Robotics, Vol. 3, No. 2, April, 1996, pp. 13-23.

[8] Faisandier, J., Les mecanismeshidrauligues, Dunod, Paris, 1957. 